\title{
Effect of Vitamin $C$ as an Adjunct in Nonsurgical Periodontal Therapy in Uncontrolled Type 2 Diabetes Mellitus Patients
}

\author{
Piyapat Kunsongkeit ${ }^{1}$ Nis Okuma ${ }^{1}$ Supanee Rassameemasmaung ${ }^{1}$ Pechngam Chaivanit $^{2}$ \\ ${ }^{1}$ Department of Oral Medicine and Periodontology, Faculty of \\ Dentistry, Mahidol University, Bangkok, Thailand \\ Internal Medicine Division, Faculty of Medicine, Burapha \\ University, Chonburi, Thailand

\begin{abstract}
Address for correspondence Nis Okuma, DDS, MSC (Oral Medicine), MD, Department of Oral Medicine and Periodontology, Faculty of Dentistry, Mahidol University,No.6, Yothi Road, Ratchathewi District, Bangkok, 10400, Thailand (e-mail: nitzumo@gmail.com).
\end{abstract}

Eur J Dent 2019;13:444-449

\begin{abstract}
Keywords

- vitamin C

- nonsurgical periodontal therapy

- chronic periodontitis

- uncontrolled type 2 DM

Objective The main purpose of this article is to evaluate periodontal parameters of chronic periodontitis patients with uncontrolled type 2 diabetes mellitus after initial periodontal therapy plus vitamin $C$.

Materials and Methods A double-blind, placebo-controlled, clinical trial was conducted. Subjects received initial periodontal therapy plus $500 \mathrm{mg} /$ day vitamin $C$ for 2 months $(n=15)$ or placebo $(n=16)$. Fasting blood sugar (FBS), hemoglobin A1c (HbA1C), and plasma vitamin C level were assessed at baseline and 2 months post-treatment. Plaque Index, Sulcus Bleeding Index, Gingival Index, pocket depth, and clinical attachment level were measured at baseline, 1 month, and 2 months post-treatment. Results Almost all subjects had low level of plasma vitamin $C$ at baseline. In the test group, plasma vitamin $C$ was significantly increased to an adequate level at the end of 2 months. After periodontal treatment, FBS and HbA1c were not significantly different compared with baseline in the test group. In the control group, FBS was significantly decreased from baseline. However, no significant difference between groups was found either in FBS or $\mathrm{HbA1c}$. All periodontal parameters were significantly improved from baseline in both groups. However, no significant difference was found between groups.

Conclusion Supplementation of $500 \mathrm{mg} /$ day vitamin C did not give an additional benefit in promoting periodontal status in periodontitis patients with uncontrolled type 2 diabetes mellitus.
\end{abstract}

\section{Introduction}

The association between diabetes mellitus (DM) and periodontitis is generally accepted. ${ }^{1}$ Several explanations underlying this association are proposed. These include an increased oxidative stress in diabetic patients, ${ }^{2}$ an impaired neutrophil function, both the chemotaxis and phagocytosis ${ }^{3,4}$ as well as the induction of proinflammatory cytokine and chemokine gene expression in monocytic cells. ${ }^{5}$ Regarding the mucosal barrier function, thickening of gingival capillary basement membranes caused by microangiopathies impedes oxygen diffusion and metabolic waste elimination in the gingival tissues. ${ }^{6}$ In addition, the cross-linking of collagen fibers is reduced, thereby reducing the flexibility and permeability of tissue. ${ }^{7}$ On the other hand, the activity of collagenase is increased. ${ }^{8}$ All of these are associated with more severe periodontal tissue destruction in diabetic subjects.

Vitamin $C$ is one of the essential micronutrients for humans. It acts as an antioxidant and can promote wound healing. ${ }^{9}$ In subjects with DM, plasma vitamin $\mathrm{C}$ was significantly 
lower compared with healthy individuals. ${ }^{10}$ Low plasma vita$\min C$ is due to an increase in clearance in patients with diabetic nephropathy. ${ }^{11}$ The elevated plasma free radicals caused by hyperglycemia also reduce antioxidants including vitamin C. ${ }^{12}$

Due to its antioxidation and wound healing promotion, the effect of vitamin C supplementation in DM patients with periodontitis should be of interest. However, few studies were found.$^{13}$ Gokhale et al ${ }^{13}$ investigated the effect of vitamin C supplementation plus nonsurgical periodontal treatment on chronic periodontitis patients with freshly diagnosed type $2 \mathrm{DM}$. They reported a significant reduction in sulcus bleeding after dietary supplementation of $450 \mathrm{mg}$ vitamin C. Although the beneficial effect of vitamin $\mathrm{C}$ was demonstrated, the follow-up period was only 2 weeks. ${ }^{13}$ Thus, we aimed to evaluate, for 2 months, the effect of vitamin $C$ as an adjunct in nonsurgical periodontal therapy in chronic periodontitis patients with uncontrolled type 2 DM.

\section{Materials and Methods}

This study was a double-blind, placebo-controlled clinical trial. Ethical approval was obtained from the Faculty of Dentistry/Faculty of Pharmacy, Mahidol University, Institutional Review Board (COA.No.MU-DT/PY-IRB 2016/061.0711) and Faculty of Medicine, Burapha University (No.001/2560). The study was registered in clinicaltrials.gov (NCT03269799).

\section{Study Population}

Type 2 DM subjects were recruited from Internal Medicine Clinic, Burapha University Hospital, Chonburi. Eligible subjects were informed and those who were willing to participate were referred to Dental Clinic, Burapha University Hospital for a comprehensive periodontal examination. Subjects who fulfilled the criteria were provided with a written informed consent. Before the experiment, oral hygiene instruction and motivation were given until Plaque Index ${ }^{14}$ was $\leq 0.5$.

\section{Inclusion Criteria}

Uncontrolled type 2 DM subjects were recruited (fasting blood sugar [FBS] of $>150 \mathrm{mg} / \mathrm{dL}$ and hemoglobin A1c [HbA1c] of $>7 \%) .{ }^{15}$ Inclusion criteria for periodontitis were moderate chronic periodontitis (clinical attachment level (CAL) of $\geq 3 \mathrm{~mm}$ ) according to the previous report ${ }^{16}$ but slightly modified by selecting tooth with pocket depth (PD) of $\geq 5 \mathrm{~mm}$ in at least one tooth.

\section{Exclusion Criteria}

Subjects who affected with DM complications, receiving insulin injection ${ }^{17}$ or medications that could interact with vitamin $\mathrm{C}^{18}$ or suffered from any conditions that affected with vitamin $C$ excretion, pregnancy, smoking, ${ }^{19}$ receiving periodontal treatment or other vitamin supplementation in the previous 6 months.

\section{Sample Size Calculation and Random Allocation}

Sample size was calculated based on Sulcus Bleeding Index. ${ }^{13}$ At a two-sided type I error of $0.05,80 \%$ power of detection, a sample of 12 subjects was required. To compensate for $20 \%$ dropouts, at least 15 subjects were recruited for each group. Subjects were stratified by age and gender and randomly allocated by one researcher (SR) to the test (500 mg/day vita$\min \mathrm{C}$ ) or control (placebo) group.

\section{Baseline Examination}

The study design was shown in (-Fig. 1). Blood samples were collected for the determination of plasma vitamin C, FBS, and HbA1c. Subjects saw medical doctors for DM follow-up. Periodontal parameters were recorded by a blinded and calibrated examiner (PK). Plaque Index, Gingival Index $(\mathrm{GI}),{ }^{20}$ Sulcus Bleeding Index, ${ }^{21} \mathrm{PD}$, and CAL were recorded using a UNC-15 probe (Hu-Friedy, Illinois, United States) from one tooth with the deepest PD and without furcation involvement, periapical lesion, or endodontic involvement. Then, subjects received full mouth scaling and root planning and were prescribed $500 \mathrm{mg} /$ day vitamin C (Government Pharmaceutical Organization, Thailand) or size- and coloridentical placebo (Department of Pharmaceutical Industry, Faculty of Pharmacy, Mahidol University, Thailand). Vitamin $C$ or placebo was kept in the concealed plastic bags and was prescribed for a duration of 30 days at a time.

\section{One-Month Evaluation}

Periodontal parameters and any adverse effects were recorded. Residual vitamin C or placebo tablets were counted for an indirect evaluation of patients' compliance. Vitamin $\mathrm{C}$ or placebo was prescribed for another 1 month.

\section{Two-Month Evaluation}

Blood sample was collected. Periodontal parameters were recorded. Residual vitamin $\mathrm{C}$ or placebo tablets were counted. Adverse effects, if any, were recorded.

\section{Statistical Analysis}

Data were analyzed using SPSS for Windows (version 23). Within and between group comparisons of plasma vitamin C, FBS and HbA1c were done using Wilcoxon signed rank test and Mann-Whitney U test, respectively. Within and between group, comparisons of periodontal parameters were done using Friedman test and Mann-Whitney U test, respectively. For multiple intragroup comparison, Bonferroni post-hoc test was performed. Significant level was set at $p \leq 0.05$ for all tests.

\section{Results}

Thirty-one subjects were participated. None of them was withdrawn from the study. Subject characteristics at baseline were shown in ( - Table 1). No statistical significance in subject characteristics was found between groups.

\section{Level of Plasma Vitamin C, Fasting Blood Sugar, and Hemoglobin A1c}

At baseline, 73 and $68 \%$ of subjects in the test and control group, respectively, had deficient to low plasma vitamin C level ( $<23 \mu \mathrm{mol} / \mathrm{L}$ according to Jacob and Sotoudeh ${ }^{22}$ ). No significant difference in plasma vitamin C, FBS, and HbA1c was found between groups ( - Table 2 ). 


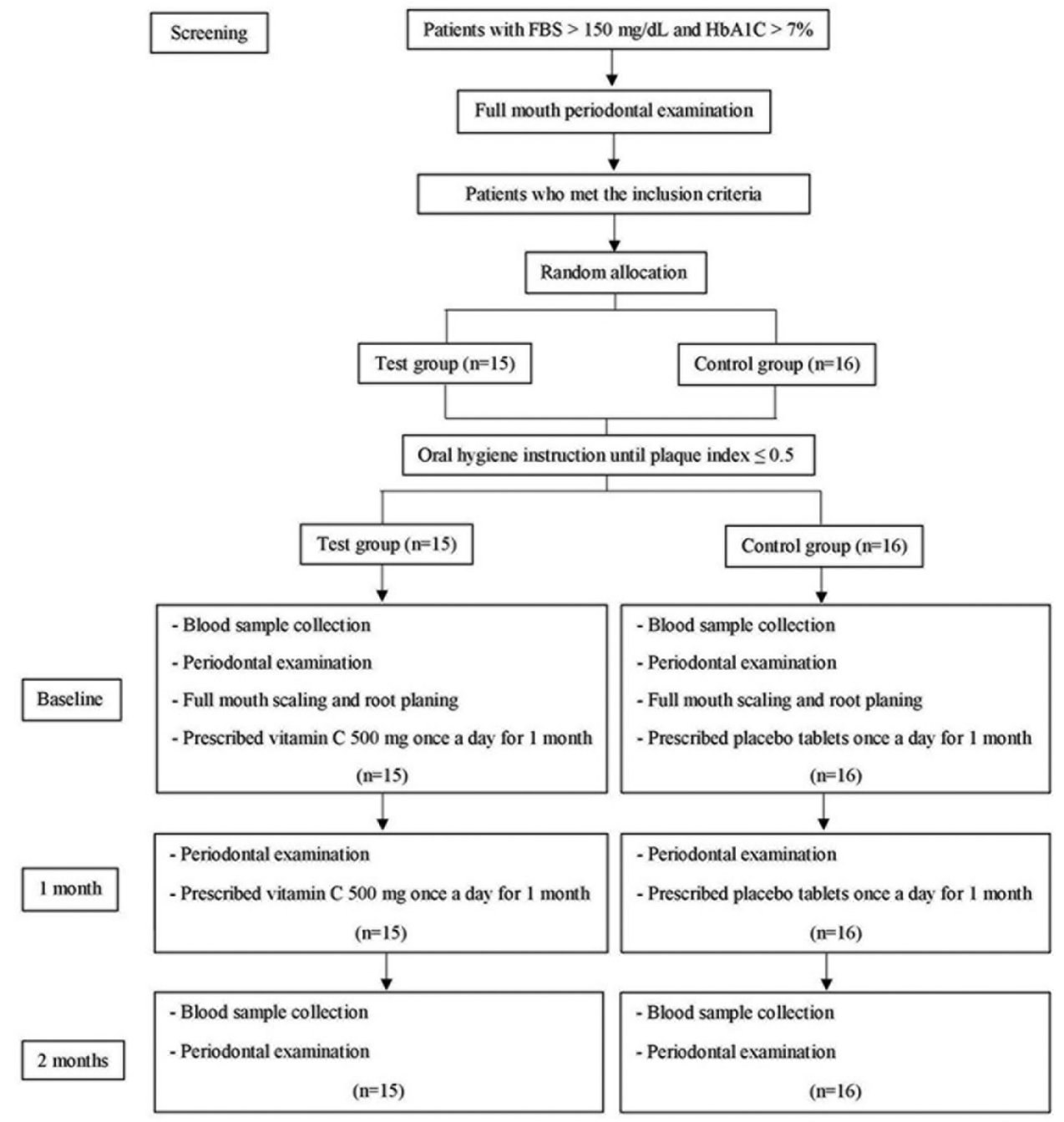

Fig. 1 Study design.

Table 1 Subject characteristics at baseline

\begin{tabular}{|l|l|l|}
\hline & Test $(\boldsymbol{n}=15)$ & $\begin{array}{l}\text { Control } \\
(\boldsymbol{n}=16)\end{array}$ \\
\hline Age (years) & $59.87 \pm 11.3$ & $57.94 \pm 14.0$ \\
\hline No. (\%) of female & $11(73.3)$ & $11(68.8)$ \\
\hline No. (\%) of male & $4(26.7)$ & $5(31.3)$ \\
\hline $\begin{array}{l}\text { Duration of type 2 diabetes } \\
\text { mellitus (year) }\end{array}$ & $7.86 \pm 4.16$ & $7.64 \pm 4.42$ \\
\hline
\end{tabular}

At 2-month evaluation, plasma vitamin $C$ in the test group was significantly elevated compared with baseline and the control group. In the test group, FBS and HbA1c were not significantly different compared with baseline. In the control group, FBS was significantly decreased from baseline. However, no significant difference between groups was found either in FBS or HbA1c.

\section{Periodontal Parameters}

At baseline, no any parameter was significantly different between groups ( $\mathbf{-}$ Table 3 ). Throughout the study, subjects could control their oral hygiene status. Sulcus bleeding index, GI, PD, and CAL were significantly different compared with baseline, indicating periodontal improvement in both groups. However, no significant difference in all periodontal parameters was found between groups at any time interval.

\section{Adverse Effect and Compliance}

No adverse effect was reported. Both groups complied to the course of vitamin $\mathrm{C}$ or placebo.

\section{Discussion}

Periodontitis is an inflammatory condition that enhances the generation of reactive oxygen species. ${ }^{23}$ However, hyperglycemia increases free radical concentration, leading to the reduction in pancreatic $\beta$ cell function and induction of insulin resistance and poor glycemic control. ${ }^{12}$ Vitamin $\mathrm{C}$, as an antioxidant, can decrease oxidative stress. ${ }^{24}$ Along with its wound healing promotion effect, ${ }^{24,25}$ we questioned that vitamin $C$ supplementation plus nonsurgical periodontal therapy could improve periodontal parameters in subjects with uncontrolled type 2 DM. 
Table 2 Level of plasma vitamin C, fasting blood sugar, and hemoglobin A1C

\begin{tabular}{|c|c|c|c|c|}
\hline & & Test & Control & $p$-Value \\
\hline \multirow[t]{4}{*}{ Plasma vitamin $C(\mu \mathrm{mol} / \mathrm{L})$} & Baseline & $18.54 \pm 11.00$ & $20.01 \pm 18.84$ & 0.599 \\
\hline & 2 months & $27.77 \pm 15.55$ & $17.40 \pm 14.90$ & $0.049^{\mathrm{b}}$ \\
\hline & Difference between baseline -2 months & $9.23 \pm 14.57$ & $-2.62 \pm 9.31$ & $0.017^{b}$ \\
\hline & $p$-Value & $0.036^{\mathrm{a}}$ & 0.179 & \\
\hline \multirow[t]{4}{*}{ FBS (mg/dL) } & Baseline & $168.53 \pm 16.62$ & $179 \pm 49.04$ & 0.654 \\
\hline & 2 months & $165.87 \pm 51.76$ & $170.13 \pm 59.76$ & 0.861 \\
\hline & Difference between baseline-2 months & $-2.67 \pm 52.81$ & $-8.88 \pm 36.08$ & 0.953 \\
\hline & $p$-Value & 0.280 & $0.046^{\mathrm{a}}$ & \\
\hline \multirow[t]{4}{*}{$\mathrm{HbA1c}(\%)$} & Baseline & $7.53+0.79$ & $8.39 \pm 1.50$ & 0.202 \\
\hline & 2 months & $7.27 \pm 0.88$ & $7.98 \pm 1.85$ & 0.423 \\
\hline & Difference between baseline-2 months & $-0.26 \pm 0.80$ & $-0.41 \pm 0.89$ & 0.599 \\
\hline & $p$-Value & 0.279 & 0.059 & \\
\hline
\end{tabular}

Abbreviations: FBS, fasting blood sugar; HbA1c, hemoglobin A1c.

Statistical significance at $p<0.05$.

ailcoxon signed rank test.

bMann-Whitney U test.

Table 3 Periodontal parameters

\begin{tabular}{|c|c|c|c|c|c|c|c|c|}
\hline & & Test & & & Control & & & $p$-Value \\
\hline \multirow[t]{4}{*}{ Plaque Index } & Baseline & $0.37 \pm 0.14$ & \multirow[t]{2}{*}{$l^{a}$} & \multirow[t]{3}{*}{$1^{a}$} & $0.33 \pm 0.11$ & \multirow[t]{2}{*}{]$^{a}$} & \multirow[t]{3}{*}{$1^{a}$} & 0.358 \\
\hline & 1 month & $0.24 \pm 0.11$ & & & $0.26 \pm 0.12$ & & & 0.770 \\
\hline & 2 months & $0.15 \pm 0.07$ & & & $0.16 \pm 0.08$ & & & 0.770 \\
\hline & $p$-Value & $<0.001^{b}$ & & & $<0.001^{b}$ & & & \\
\hline \multirow[t]{4}{*}{ Sulcus Bleeding Index } & Baseline & $3.22 \pm 0.46$ & \multirow[t]{2}{*}{\}$^{a}$} & \multirow[t]{3}{*}{$1^{a}$} & $3.00 \pm 045$ & \multirow[t]{2}{*}{$l^{a}$} & \multirow[t]{3}{*}{$1^{a}$} & 0.188 \\
\hline & 1 month & $1.9 \pm 0.59$ & & & $2.00 \pm 0.57$ & & & 0.861 \\
\hline & 2 months & $0.57 \pm 0.24$ & & & $0.59 \pm 0.24$ & & & 0.830 \\
\hline & $p$-Value & $<0.001^{b}$ & & & $<0.001^{b}$ & & & \\
\hline \multirow[t]{4}{*}{ Gingival Index } & Baseline & $1.04 \pm 0.34$ & \multirow[t]{2}{*}{\}$^{a}$} & \multirow[t]{3}{*}{$1^{a}$} & $1.15 \pm 0.32$ & \multirow[t]{2}{*}{$l^{a}$} & \multirow[t]{3}{*}{$1^{a}$} & 0.401 \\
\hline & 1 month & $0.60 \pm 0.16$ & & & $0.66 \pm 0.21$ & & & 0.520 \\
\hline & 2 months & $0.42 \pm 0.09$ & & & $0.45 \pm 0.10$ & & & 0.572 \\
\hline & $p$-Value & $<0.001^{\mathrm{b}}$ & & & $<0.001^{b}$ & & & \\
\hline \multirow[t]{4}{*}{ Pocket depth (mm) } & Baseline & $5.2 \pm 0.41$ & \multirow[t]{2}{*}{\}$^{a}$} & \multirow[t]{3}{*}{$1^{a}$} & $5.63 \pm 1.09$ & \multirow[t]{2}{*}{$l^{a}$} & \multirow[t]{3}{*}{$1^{a}$} & 0.358 \\
\hline & 1 month & $3.25 \pm 1.09$ & & & $3.73 \pm 1.09$ & & & 0.151 \\
\hline & 2 months & $3.25 \pm 0.96$ & & & $3.6 \pm 0.90$ & & & 0.232 \\
\hline & $p$-Value & $<0.001^{b}$ & & & $<0.001^{b}$ & & & \\
\hline \multirow{4}{*}{$\begin{array}{l}\text { Clinical attachment level } \\
(\mathrm{mm})\end{array}$} & Baseline & $5.31 \pm 0.72$ & \multirow[t]{2}{*}{$\prod^{a}$} & \multirow[t]{3}{*}{$1^{a}$} & $6.05 \pm 1.73$ & \multirow[t]{2}{*}{]$^{a}$} & \multirow[t]{3}{*}{$1^{a}$} & 0.247 \\
\hline & 1 month & $3.66 \pm 1.51$ & & & $4.13 \pm 1.73$ & & & 0.401 \\
\hline & 2 months & $3.78 \pm 1.17$ & & & $3.93 \pm 1.41$ & & & 0.892 \\
\hline & $p$-Value & $0.001^{b}$ & & & $0.001^{b}$ & & & \\
\hline
\end{tabular}

Statistical significance at $p<0.05$.

${ }^{a}$ Bonferroni post-hoc test.

bFriedman test. 
In this study, vitamin $C$ at a dose of 500 mg daily was chosen according to the previous studies. ${ }^{13,26}$ Gokhale et al ${ }^{13}$ reported that scaling and root planning plus $450 \mathrm{mg} / \mathrm{day}$ of vitamin $C$ in chronic periodontitis subjects with freshly diagnosed type 2 DM resulted in a significant sulcus bleeding reduction. Levine et $\mathrm{al}^{26}$ demonstrated that after single dose of $500 \mathrm{mg}$ and higher, the bioavailability of vitamin $\mathrm{C}$ declined and excretion increased. At 1,000 mg of vitamin C, oxalate and urate excretion were elevated. ${ }^{26}$

After initial periodontal treatment, periodontal health was improved without significant difference between groups. Our result was inconsistent to the previous study ${ }^{13}$ and probably due to the difference in subject characteristics. Subjects in the study of Gokhale et al $^{13}$ were freshly diagnosed type 2 DM, while those in our study were uncontrolled type 2 DM. It is known that severity and progression of periodontal disease are increased in uncontrolled DM patients. ${ }^{27}$ Moreover, some subjects in our study had an adequate plasma vitamin $\mathrm{C}$ level at baseline (data not shown). Thus, vitamin C supplementation to adequately nourished people might not affect with periodontal integrity. ${ }^{22,28}$ These two factors might mask the beneficial effect of vitamin $C$.

Periodontitis and DM have a bidirectional relationship..$^{29,30}$ However, the effect of periodontal therapy on glycemic control was still in doubt ${ }^{29,31}$ and was not the objective of the present study. It was shown that nonsurgical periodontal therapy in diabetic patients could reduce HbA1c by $\sim 0.4 \% .{ }^{29}$ In this study, HbA1c was reduced after initial periodontal treatment, but the reduction was not significant in both groups. Our result was supported by Mizuno et $\mathrm{al}^{31}$ that nonsurgical periodontal treatment improved systemic oxidative stress balance and quality of life, but did not significantly decrease HbA1c levels at 3 months follow-up in type 2 DM patients. ${ }^{31}$ Indeed, level of glycemic control depends on factors other than periodontal treatment, for example, behavior, sugar and food intake, exercise, stress, use of hypoglycemic medication, duration of treatment, and level of education. ${ }^{32,33}$ Another explanation is the study period of 2 months was inadequate to observe the change in glycemic control. Although the reduction in HbA1c was not statistically significant $(0.26 \%$ in the test group and $0.41 \%$ in the control group), it could have a clinical impact since it could reduce the risk of microvascular complication and mortality rate by more than $10 \%$ at the population level. ${ }^{34}$ Thus, we agreed with Casanova et $\mathrm{al}^{29}$ that periodontal treatment should be a part of the overall management of DM. ${ }^{29}$

Supplementation of $500 \mathrm{mg} /$ day vitamin C for 2 months did not affect FBS and HbA1c in this study. This finding might be explained by the study of Yue et $\mathrm{al}^{35}$ that both plasma ascorbic acid and its urinary excretion correlated inversely with glycosylated hemoglobin level. In addition, abnormalities of vitamin C metabolism and its higher turnover were found in diabetics patients over the normal volunteers. ${ }^{36}$

In conclusion, supplementation of $500 \mathrm{mg} /$ day vitamin C plus initial periodontal therapy in periodontitis subjects with uncontrolled type $2 \mathrm{DM}$ did not give an additional benefit in promoting periodontal status.

\section{Conflict of Interest}

None declared.

\section{Acknowledgments}

The authors would like to thank the Faculty of Dentistry, Mahidol University for a grant of this study.

\section{References}

1 Emrich LJ, Shlossman M, Genco RJ. Periodontal disease in non-insulin-dependent diabetes mellitus. J Periodontol 1991;62(2):123-131

2 Patil VS, Patil VP, Gokhale N, Acharya A, Kangokar P. Chronic periodontitis in type 2 diabetes mellitus: oxidative stress as a common factor in periodontal tissue injury. J Clin Diagn Res 2016;10(4):BC12-BC16

3 Golub LM, Nicoll GA, Iacono VJ, Ramamurthy NS. In vivo crevicular leukocyte response to a chemotactic challenge: inhibition by experimental diabetes. Infect Immun 1982;37(3):1013-1020

4 Alba-Loureiro TC, Munhoz CD, Martins JO, et al. Neutrophil function and metabolism in individuals with diabetes mellitus. Braz J Med Biol Res 2007;40(8):1037-1044

5 Shanmugam N, Reddy MA, Guha M, Natarajan R. High glucose-induced expression of proinflammatory cytokine and chemokine genes in monocytic cells. Diabetes 2003;52(5):1256-1264

6 Frantzis TG, Reeve CM, Brown AL, Jr. The ultrastructure of capillary basement membranes in the attached gingiva of diabetic and nondiabetic patients with periodontal disease. J Periodontol 1971;42(7):406-411

7 Paul RG, Bailey AJ. Glycation of collagen: the basis of its central role in the late complications of ageing and diabetes. Int J Biochem Cell Biol 1996;28(12):1297-1310

8 Ramamurthy NS, Golub LM. Diabetes increases collagenase activity in extracts of rat gingiva and skin. J Periodontal Res 1983;18(1):23-30

9 Packer L, Fuchs J, Vitamin C in Health and Disease. New York: Marcel Dekker1997

10 Will JC, Ford ES, Bowman BA. Serum vitamin C concentrations and diabetes: findings from the Third National Health and Nutrition Examination Survey, 1988-1994. Am J Clin Nutr 1999;70(1):49-52

11 Hirsch IB, Atchley DH, Tsai E, Labbé RF, Chait A. Ascorbic acid clearance in diabetic nephropathy. J Diabetes Complications 1998;12(5):259-263

12 Ceriello A. Oxidative stress and glycemic regulation. Metabolism 2000;49(2 Suppl $1: 27-29$

13 Gokhale NH, Acharya AB, Patil VS, Trivedi DJ, Thakur SL. A short-term evaluation of the relationship between plasma ascorbic acid levels and periodontal disease in systemically healthy and type 2 diabetes mellitus subjects. J Diet Suppl 2013;10(2):93-104

14 Greene JC, Vermillion JR. The simplified oral hygiene index. J Am Dent Assoc 1964;68:7-13

15 American Diabetes Association. Standards of medical care in diabetes 2018. Diabetes Care 2018;2018:41

16 Wiebe CB, Putnins EE. The periodontal disease classification system of the American Academy of Periodontology-an update. J Can Dent Assoc 2000;66(11):594-597

17 Paolisso G, D'Amore A, Balbi V, et al. Plasma vitamin C affects glucose homeostasis in healthy subjects and in non-insulin-dependent diabetics. Am J Physiol 1994;266 (2 Pt 1): E261-E268 
18 Alagl AS, Bhat SG. Ascorbic acid: new role of an age-old micronutrient in the management of periodontal disease in older adults. Geriatr Gerontol Int 2015;15(3):241-254

19 Schectman G, Byrd JC, Gruchow HW. The influence of smoking on vitamin $C$ status in adults. Am J Public Health 1989;79(2):158-162

20 Loe H, Silness J. Periodontal disease in pregnancy. I. Prevalence and severity. Acta Odontol Scand 1963;21:533-551

21 Mühlemann HR, Son S. Gingival sulcus bleeding-a leading symptom in initial gingivitis. Helv Odontol Acta 1971;15(2):107-113

22 Jacob RA, Sotoudeh G. Vitamin C function and status in chronic disease. Nutr Clin Care 2002;5(2):66-74

23 Wang Y, Andrukhov O, Rausch-Fan X. Oxidative stress and antioxidant system in periodontitis. Front Physiol 2017;8:910

24 Chapple IL. Potential mechanisms underpinning the nutritional modulation of periodontal inflammation. J Am Dent Assoc 2009;140(2):178-184

25 Mohammed BM, Fisher BJ, Kraskauskas D, et al. Vitamin C promotes wound healing through novel pleiotropic mechanisms. Int Wound J 2016;13(4):572-584

26 Levine M, Conry-Cantilena C, Wang Y, et al. Vitamin C pharmacokinetics in healthy volunteers: evidence for a recommended dietary allowance. Proc Natl Acad Sci USA 1996;93(8):3704-3709

27 Ryan ME, Carnu O, Kamer A. The influence of diabetes on the periodontal tissues. J Am Dent Assoc 2003;134(Spec No): $34 \mathrm{~S}-40 \mathrm{~S}$
28 Vogel RI, Lamster IB, Wechsler SA, Macedo B, Hartley LJ, Macedo JA. The effects of megadoses of ascorbic acid on PMN chemotaxis and experimental gingivitis. J Periodontol 1986;57(8):472-479

29 Casanova L, Hughes FJ, Preshaw PM. Diabetes and periodontal disease: a two-way relationship. $\mathrm{Br}$ Dent J 2014;217(8):433-437

30 Preshaw PM, Alba AL, Herrera D, et al. Periodontitis and diabetes: a two-way relationship. Diabetologia 2012;55(1):21-31

31 Mizuno H, Ekuni D, Maruyama T, et al. The effects of non-surgical periodontal treatment on glycemic control, oxidative stress balance and quality of life in patients with type 2 diabetes: a randomized clinical trial. PLoS One 2017;12(11):e0188171

32 Ahmad NS, Islahudin F, Paraidathathu T. Factors associated with good glycemic control among patients with type 2 diabetes mellitus. J Diabetes Investig 2014;5(5):563-569

33 Yigazu DM, Desse TA. Glycemic control and associated factors among type 2 diabetic patients at Shanan Gibe Hospital, Southwest Ethiopia. BMC Res Notes 2017;10(1):597

34 Simpson TC, Weldon JC, Worthington HV, et al. Treatment of periodontal disease for glycaemic control in people with diabetes mellitus. Cochrane Database Syst Rev 2015; (11):CD004714

35 Yue DK, McLennan S, McGill M, et al. Abnormalities of ascorbic acid metabolism and diabetic control: differences between diabetic patients and diabetic rats. Diabetes Res Clin Pract 1990;9(3):239-244

36 Som S, Basu S, Mukherjee D, et al. Ascorbic acid metabolism in diabetes mellitus. Metabolism 1981;30(6):572-577 